\title{
Review of zincblende ZnO: Stability of metastable ZnO phases
}

\author{
A. Ashrafi ${ }^{\text {a) }}$ and C. Jagadish \\ Department of Electronic Materials Engineering, Research School of Physical Sciences and Engineering, \\ The Australian National University, Canberra, Australian Capital Territory 0200, Australia
}

(Received 18 June 2007; accepted 23 July 2007; published online 1 October 2007)

Common II-VI compound semiconducting materials are stable thermodynamically with zincblende phase, while the II-O materials such as zinc oxide $(\mathrm{ZnO})$ and beryllium oxide $(\mathrm{BeO})$ are stable with wurtzite phase, and cadmium oxide $(\mathrm{CdO})$ and magnesium oxide $(\mathrm{MgO})$ are stable in rocksalt phase. This phase disharmony in the same material family laid a challenge for the basic physics and in practical applications in optoelectronic devices, where ternary and quaternary compounds are employed. Thermodynamically the zincblende $\mathrm{ZnO}$ is a metastable phase which is free from the giant internal electric fields in the [001] directions and has an easy cleavage facet in the $\langle 110\rangle$ directions for laser cavity fabrication that combined with evidence for the higher optical gain. The zincblende materials also have lower ionicity that leads to the lower carrier scattering and higher doping efficiencies. Even with these outstanding features in the zincblende materials, the growth of zincblende $\mathrm{ZnO}$ and its fundamental properties are still limited. In this paper, recent progress in growth and fundamental properties of zincblende $\mathrm{ZnO}$ material has been reviewed.

(C) 2007 American Institute of Physics. [DOI: 10.1063/1.2787957]

\section{TABLE OF CONTENTS}

I. INTRODUCTION. . . . . . . . . . . . . .

A. Common II-O material phases...........

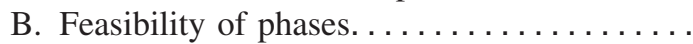

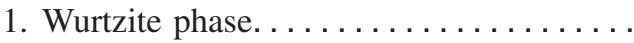

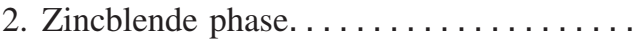

C. Band structure of $\mathrm{ZnO} \ldots \ldots \ldots \ldots \ldots$

II. GROWTH OF ZINCBLENDE ZNO..........

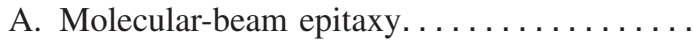

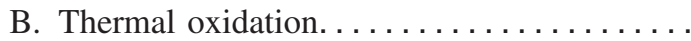

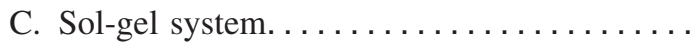

III. STRUCTURAL PROPERTIES. . . . . . . . . .

A. Phase stability of $\mathrm{ZnO} \ldots \ldots \ldots \ldots \ldots \ldots$

1. Theoretical studies................

2. Experimental results. $\ldots \ldots \ldots \ldots \ldots$.

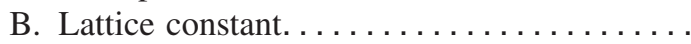

C. Polytypism in $\mathrm{ZnO} \ldots \ldots \ldots \ldots \ldots \ldots$

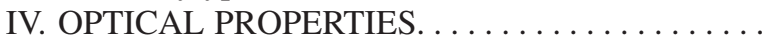

A. Far- and near-field photoluminescences......

B. Comparative studies of luminescence.......

V. TRANSPORT PROPERTIES................

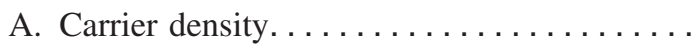

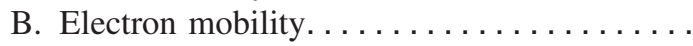

VI. CONCLUSION AND OUTLOOK. . . . . . . . 10

\footnotetext{
${ }^{a}$ Author to whom correspondence should be addressed. Electronic mail: almamun.ashrafi@anu.edu.au. On leave from Department of Physics, University of Dhaka, Bangladesh.
}

\section{INTRODUCTION}

Common II-VI compound materials have been at the center of semiconductor research for a long time along with the III-V materials. It has been expected that the II-VI semiconductors will provide the material basis for a number of well-established technologies, as well as new classes of electronic and optoelectronic devices. The operation characteristics of these devices, however, depend critically on the physical and structural properties of the constituent materials, such as different crystal phases that are often made into complex quantum structures to confine carriers on the order of a nanometer. To exploit this flexibility both in basic physics and devices, the II-VI material family has to be aligned along the same structural phases. Unfortunately, most of these II-VI materials, such as $\mathrm{ZnS}$, ZnTe, and $\mathrm{ZnSe}$ are stable thermally with zincblende phases, while the II-VI oxide (II-O) materials crystallize in the rocksalt and wurtzite phases. ${ }^{1}$ For a clear layout of this thermal stability of phases in the II-VI material family, the bandgap energy versus lattice constant has been plotted in Fig. 1. It shows that the common II-VI materials are aligned along the same lattice constant as GaAs substrate, while the II-O materials are close to the lattice constants of $\mathrm{Al}_{2} \mathrm{O}_{3}$ and $\mathrm{SiC}$ substrates.

\section{A. Common II-O material phases}

The most common II-O binary compound semiconducting materials are $\mathrm{ZnO}, \mathrm{BeO}, \mathrm{MgO}$, and $\mathrm{CdO}$. Thermodynamically the $\mathrm{ZnO}$ and $\mathrm{BeO}$ materials are stable in the wurtzite structure, while the $\mathrm{MgO}$ and $\mathrm{CdO}$ materials are stable in the rocksalt structure. Table I shows the thermodynamically stable phases of the common II-VI and II-O materials. These 


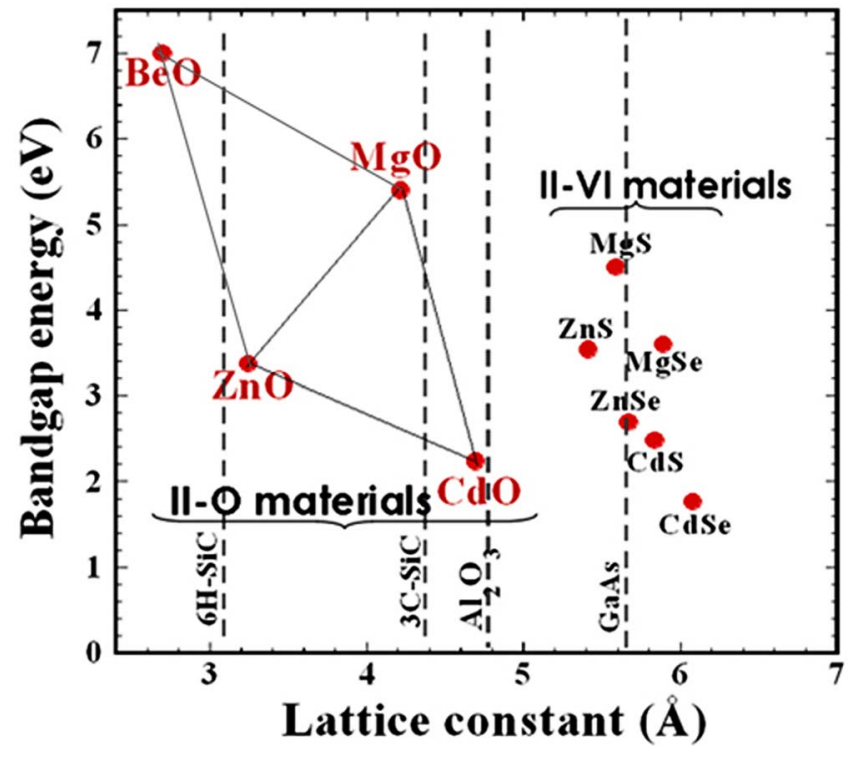

FIG. 1. (Color online) The bandgap energies of II-VI and II-O materials as a function of lattice constant have been plotted. It is a clear layout of physical positions of II-O among the common II-VI materials. The $\mathrm{SiC}, \mathrm{GaAs}$, and $\mathrm{Al}_{2} \mathrm{O}_{3}$ substrates are shown with lattice constants close to those of the II-O and II-VI materials, respectively.

different crystal structures in the same material family have to be solved by constructing the stable heterostructures with the II-O as well as with the common II-VI materials for the fundamental studies of basic physics and applications in spintronic and optoelectronic devices operating in the blue to ultraviolet spectral region. It is expected that there are two ways to master this structural mismatch problem in the II-VI material family: by converting (i) the rocksalts $\mathrm{CdO}$ and $\mathrm{MgO}$ into the wurtzite and/or (ii) the II-O materials into the zincblende structure.

\section{B. Feasibility of phases}

Crystallographically the atomic arrangement of zincblende structure is quite similar to that of the wurtzite structure - only the angle of adjacent tetrahedral units is different, having values of $60^{\circ}$ for zincblende and $0^{\circ}$ for wurtzite phase. For a clear layout of these structural phases, the basic crystal structures of wurtzite and zincblende $\mathrm{ZnO}$ are represented schematically in Fig. 2. The $\mathrm{Zn}$ and $\mathrm{O}$ atoms are marked in the schematic with ash and blue circles, respec-

TABLE I. Thermodynamically stable phases of II-VI and II-O materials are shown. Most of the II-VI materials are stabilized with zincblende phase, while the II-O materials stabilize with different crystal structures. Here, RS, $\mathrm{ZB}$, and $\mathrm{WZ}$ denote the rocksalt, zincblende, and wurtzite structures, respectively.

\begin{tabular}{ccccc}
\hline \hline & $\mathrm{O}$ & $\mathrm{S}$ & $\mathrm{Se}$ & $\mathrm{Te}$ \\
\hline $\mathrm{Mg}$ & $\mathrm{RS}$ & $\mathrm{RS}$ & $\mathrm{RS}$ & $\mathrm{WZ}$ \\
$\mathrm{Zn}$ & $\mathrm{WZ}$ & $\mathrm{ZB}$ & $\mathrm{ZB}$ & $\mathrm{ZB}$ \\
$\mathrm{Cd}$ & $\mathrm{RS}$ & $\mathrm{WZ}$ & $\mathrm{ZB}$ & $\mathrm{ZB}$ \\
$\mathrm{Be}$ & $\mathrm{WZ}$ & $\mathrm{ZB}$ & $\mathrm{ZB}$ & ZB \\
\hline \hline
\end{tabular}

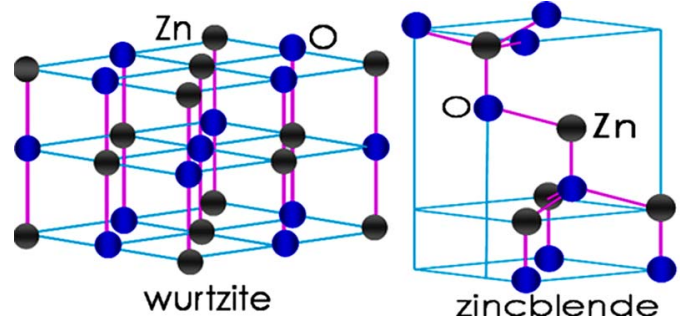

FIG. 2. (Color online) A schematic representation of $\mathrm{ZnO}$ crystal structures: (a) wurtzite and (b) zincblende. The $\mathrm{Zn}$ and $\mathrm{O}$ atoms are marked as well in the schematic with ash and blue circles, respectively.

tively. In this review, however, we will restrain our results and discussion to zincblende $\mathrm{ZnO}$ and in some cases, to wurtzite $\mathrm{ZnO}$ thin layers.

\section{Wurtzite phase}

$\mathrm{ZnO}$ is stable thermodynamically with the wurtzite phase due to its ionicity that resides exactly at the borderline between the covalent and the ionic materials. It is at the "ionic extreme" of tetragonally coordinated compound semiconductors, which cubic and hexagonal structures lead to their classification as covalently bonded bulk materials. $\mathrm{ZnO}$ is thus the prototype of tetragonally coordinated ionic semiconductor. Figure 3 shows Phillip's ionicity and energy of stacking faults $\left(E_{\mathrm{SF}}\right)$ of $\mathrm{ZnO}$ and related materials as a function of $c / a$ ratio. The stacking faults in a material are the result of compressive and/or tensile strain, together with the imbalanced interface chemistry of the respective material system. The higher the $c / a$ ratio in the crystal, the lower is the stacking fault energy, together with the smaller ionicity, as shown in Fig. 3.

Wurtzite $\mathrm{ZnO}$ has a lack of center of inversion symmetry due to the $P 6_{3} m c$ space group, which is the origin for piezoelectricity in the $\mathrm{ZnO}$ material. In addition, due to the $c$ axis oriented growth of wurtzite $\mathrm{ZnO}$ layers, the macroscopic polarization is induced in the absence of the external fields, which is the result of a strain-induced polarization. In prin-

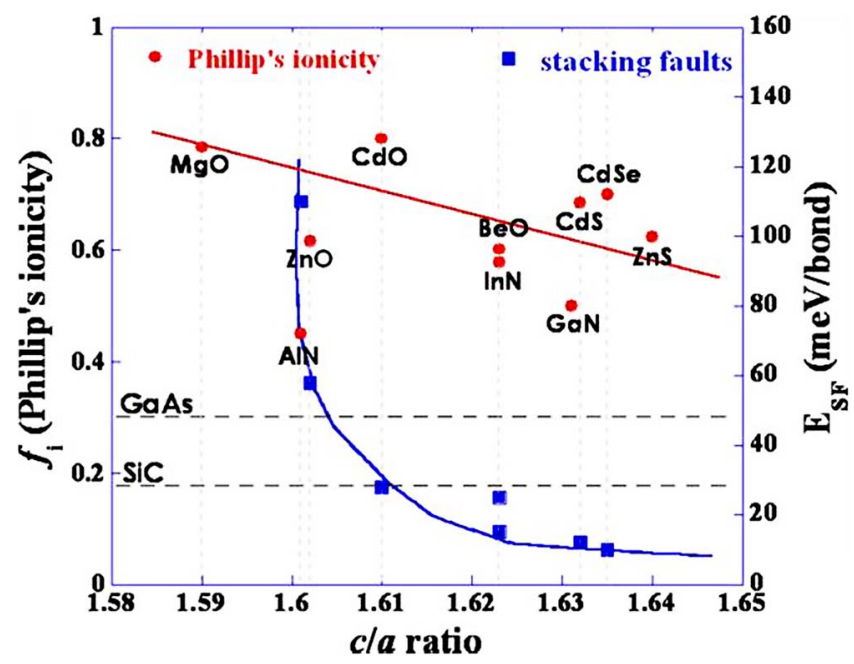

FIG. 3. (Color online) Phillip's ionicity and stacking fault energy $\left(E_{\mathrm{SF}}\right)$ in the common II-VI and II-O materials as a function of $c / a$ ratio of the crystals. 
ciple, the strain-induced polarization $\bar{P}$ generates electric fields $\bar{E}$ and/or displacement field vector $\bar{D}$ with $\bar{D}=\kappa \bar{E}_{0}$ $+4 \pi \bar{P}$, where $\kappa=1+4 \pi \eta$ and $\eta$ is the susceptibility. The polarization $\bar{P}$ can simply be represented by $\bar{P}$ $=\tanh \left(\Delta \bar{E} / 2 k_{B} T\right)$, where $\Delta \bar{E}=g \mu_{B} \bar{B}$, which finally contributes to the quenching of excitonic properties in the wurtzite materials. In principle, there are three piezoelectric strain coefficients for the $\mathrm{ZnO}$ material as $d_{15}, d_{31}$, and $d_{33}$ with the corresponding values of $-10 \times 10^{-12},-5 \times 10^{-12}$, and 12 $\times 10^{-12} \mathrm{~m} / \mathrm{V}$, respectively. ${ }^{2}$

Sanderson empirically found that the cohesive energy $\left(E_{0}\right)$ of the prototype materials can simply be described as the average energy of fully covalent and fully ionic chemical bonds by $E_{0}=\left(1-f_{i}\right) E_{\mathrm{cov}}+f_{i} E_{\text {ion }}$, where $f_{i}$ denotes the fractional ionic characteristic, and $E_{\mathrm{cov}}$ and $E_{\text {ion }}$ are the energies of hypothetical octet compounds consisting of fully covalent and fully ionic chemical bonds, respectively. ${ }^{3}$ Considering this theoretical approach, the system energy of polytypism of a material can be described by ${ }^{4}$

$$
E=E_{0}-\sum_{i, n} J_{n} \sigma_{i} \sigma_{i+n}
$$

where $E_{0}$ is the energy of crystal, $J_{n}$ is the interaction energy between the $n$th neighbor layers, which finally contribute to the cohesive energy, $\sigma$ is the spin parameter defined in terms of ordering between the adjacent layers, and the summations are over all layers. A systematic structural trend in the bulk form has been accomplished by a simple description of energy difference $\left(\Delta E_{\mathrm{WZ}-Z \mathrm{~B}}\right)$ between the wurtzite and zincblende phases.

\section{Zincblende phase}

A number of studies have been addressed with wurtzite $\mathrm{ZnO}$ epitaxy, while a few experimental and theoretical literatures are found on metastable zincblende $\mathrm{ZnO}$ growth and its fundamental properties. The zincblende materials have lower ionicity compared to the wurtzite materials that has been represented as a function of $c / a$ ratio in Fig. 3, indicating that the zincblende materials are absolutely covalent-viable for application in semiconductor technology. ${ }^{5}$ In the zincblende and wurtzite structures, each $\mathrm{Zn}$ (or $\mathrm{O}$ ) has four nearest neighbors; the in-plane bonds are stronger, as indicated by higher electron density, than the out-of-plane bonds. In contrast to the zincblende/wurtzite structures, each $\mathrm{Zn}$ (or O) has six nearest neighbors in the rocksalt structure.

Owing to the higher crystallographic symmetry in the zincblende structure, it is expected that zincblende II-VI materials will have several advantages for device applications, such as lower carrier scattering, higher doping efficiencies, etc. $^{6}$ The zincblende phase has the highest symmetry compatible with the existence of piezoelectric polarization under the strain in the [001] directions, which offers a plain and attractive platform for exploring the features of excitonic systems without the perturbation field. ${ }^{7}$ It also possesses technological advantages such as easier laser cavity fabrication along the $\langle 110\rangle$ directions together with the substrate, which combines with evidence for higher optical gain. ${ }^{8}$

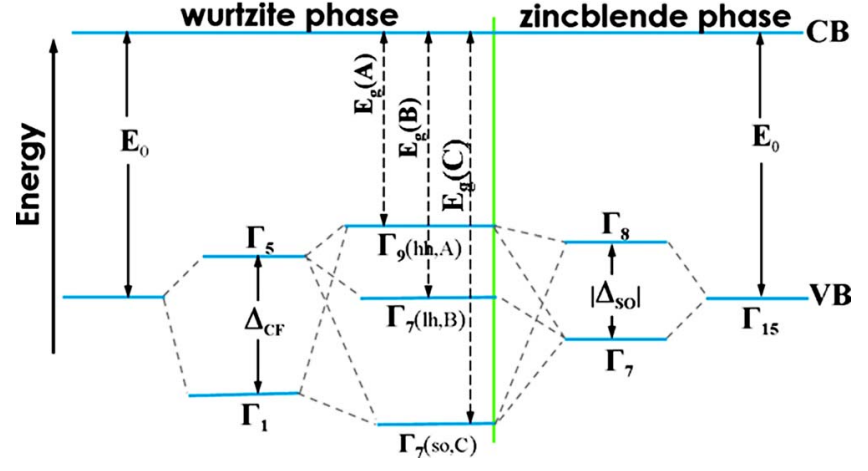

FIG. 4. (Color online) Schematic illustration of the spin-orbit splitting and crystal-field splitting in wurtzite materials as compared to zincblende $\mathrm{ZnO}$. The transitions which are allowed for various polarizations of photon electric-field vector with respect to the $c$ axis are indicated (after Ref. 11).

Moreover, the zincblende II-O materials will have the potential to be integrated with $3 C$-SiC technology, which has zincblende crystal structure.

In addition, the zincblende $\mathrm{ZnO}$ epitaxy can lead to resolution of the long standing debate over whether the ordering of the valance band in $\mathrm{ZnO}$ should be the usual one $\mathrm{e}^{9}$ or an inverted valence band ordering ${ }^{10}$ since the dispersion of valence bands in wurtzite structure is difficult to calculate using the first principles. On the counterpart in zincblende structure, the complete band dispersion of valence and conduction bands reliably provides necessary band structure parameters, such as effective masses or equivalent $k p$ parameters for device modeling. ${ }^{11}$

\section{Band structure of $\mathrm{ZnO}$}

Although the ordering of the crystal-field and spin-orbit coupling split states of the valence band (VB) maximum in $\mathrm{ZnO}$ has been a subject of controversy, a typical band structure of zincblende and wurtzite $\mathrm{ZnO}$ phases is represented schematically in Fig. 4. The zincblende crystal consists of two interpenetrating face-centered-cubic lattices, one having a group-II element atom (e.g., $\mathrm{Zn}$ ) and the other, a group-VI element atom (e.g., O). The matrix elements of the momentum operator between the conduction band and the VB can be expressed in terms of a single parameter $P$ as $P$ $=-i\left(\hbar / m_{0}\right)\left\langle S\left|p_{x}\right| X\right\rangle$, where $\left\langle S\left|p_{x}\right| X\right\rangle$ is the momentum matrix element that can be represented with energy by $E_{P}$ $=\left(2 m_{0} / \hbar^{2}\right) P^{2} ; \quad E_{P}$ matrix element is one of the band parameters. ${ }^{7}$

The VB spectrum near the $\Gamma$ point is different for the zincblende and wurtzite phases. Without spin-orbit (SO) coupling the top of the VB for wurtzite structure is split into a doublet of $\Gamma_{5}$ and a singlet of $\Gamma_{1}$ states by the crystal field. An inclusion of SO coupling gives rise to three twofold degenerate bands in the VB, which are denoted as hh (heavy hole), lh (light hole), and so (spin-orbit coupling). These states correspond to $A, B$, and $C$ exciton lines in photoluminescence experiments. The symmetries of two of these three bands are of $\Gamma_{7}$ character and one of $\Gamma_{9}$ character. On the other hand in the zincblende phase, the VB spectrum near the $\Gamma$ point without the $\mathrm{SO}$ coupling for the zincblende $\mathrm{ZnO}$ originates from the sixfold degenerate $\Gamma_{15}$ state. The SO in- 
teraction splits the $\Gamma_{15}$ level into fourfold degenerate $\Gamma_{8}$ (hh and $\mathrm{lh}$ ) and doubly degenerate $\Gamma_{7}$ (so) levels. It is noted that the crystal-field interaction in the zincblende phase is free due to its crystallographic symmetry, thereby no polarization field effects along the $\langle 001\rangle$ directions.

These outstanding physical properties in the zincblende $\mathrm{ZnO}$ material, along with its largest exciton and biexciton binding energies of 60 and $15 \mathrm{meV}$ at room temperature (RT), respectively, ${ }^{12}$ triggered an additional dimension into the research field for exploring the fundamental studies of basic physics and applications to optoelectronic and spintronic devices that has long been studied in the III-N materials. To date, however, there has been a little attention paid to the growth of zincblende $\mathrm{ZnO}$ epitaxial layers and studies of their fundamental properties. In this article, recent progress in growth and properties of metastable zincblende $\mathrm{ZnO}$ material is reviewed and compared with the stable wurtzite $\mathrm{ZnO}$ material.

\section{GROWTH OF ZINCBLENDE ZNO}

Although the $\mathrm{ZnO}$ material is a promising candidate for optoelectronic and spintronic devices in parallel to $\mathrm{GaN}$, at this moment, the main challenge is to control the $p$-type conductivity - a basic necessity for the fabrication of optoelectronic devices. It is expected that the zincblende $\mathrm{ZnO}$ phase may solve this long standing problem since the metastable zincblende $\mathrm{ZnO}$ thin layers can be grown on the cubic zincblende substrates, irrespective of the deposition techniques used in the literature. As we have pointed out in the Introduction, to date, a few reports were found on the zincblende $\mathrm{ZnO}$ epitaxy. Due to a lack of suitable substrates for the zincblende $\mathrm{ZnO}$ epitaxy, as represented in Fig. 1, zincblende $\mathrm{ZnS}$ thin layers as the interlayers and/or nucleation layers have been used in almost all of the experiments. However, the single crystalline zincblende $\mathrm{ZnO}$ growth is still a challenge, together with an availability of suitable lattice-matched substrates. In principle, the lattice mismatch leads to defect generation centers, especially the misfit dislocations, resulting in complex growth geometry in the interface zone that prolongs along the growth direction and obstructs the realization of single crystalline zincblende $\mathrm{ZnO}$ epitaxy. In the following section, we have reviewed the growth conditions used to obtain zincblende $\mathrm{ZnO}$ epilayers.

\section{A. Molecular-beam epitaxy}

Ashrafi et al. ${ }^{13}$ grew the zincblende $\mathrm{ZnO}$ layers on semiinsulating $\mathrm{GaAs}(001)$ substrates by metalorganic molecularbeam epitaxy. Thin $\mathrm{ZnS}$ buffer layers have been grown on GaAs substrates and optimized to be $\sim 72 \mathrm{~nm}$, considering the best crystalline quality of $\mathrm{ZnO}$ layers. The $\mathrm{ZnS}$ buffer layer has been used to check oxidation of substrate and reduction of lattice mismatch in the $\mathrm{ZnO} / \mathrm{GaAs}$ heterostructure. The zincblende $\mathrm{ZnO}$ layers were then grown on $\mathrm{ZnS} / \mathrm{GaAs}$ at the substrate temperature of $400-600{ }^{\circ} \mathrm{C}$ using diethyl zinc and $\mathrm{O}_{2}$ plasma sources. An electron cyclotron resonance plasma source was used to excite highdensity $\mathrm{O}_{2}$ plasma with low-ion energies of $10-20 \mathrm{eV}$. High-purity $\mathrm{O}_{2}$ gas flow of 2.5-3.5 SCCM (SCCM denotes cubic centimeter per minute at STP) and $2.45 \mathrm{GHz}$ microwave power up to $200 \mathrm{~W}$ were introduced into the plasma chamber with the magnetic field set to $875 \mathrm{G}$.

\section{B. Thermal oxidation}

Lee et al. ${ }^{14}$ prepared the zincblende $\mathrm{ZnO}$ layers by thermal oxidation of zincblende $\mathrm{ZnS}$ thin layers deposited on $\mathrm{Al}_{2} \mathrm{O}_{3}(0001)$ substrates. The $\mathrm{ZnS}$ layers were deposited at $800{ }^{\circ} \mathrm{C}$ with the thickness of $\sim 3 \mathrm{~nm}$ by pulsed laser deposition (PLD). The KrF excimer laser $(\lambda=248 \mathrm{~nm}$, pulse duration time of $20 \mathrm{~ns}$, and energy density of $5 \mathrm{~mJ} / \mathrm{cm}^{2}$ ) was used as an excitation source for the ablation of the single crystal zincblende $\mathrm{ZnS}$ target. The $\mathrm{ZnS}$ thin layers were then oxidized thermally at $900{ }^{\circ} \mathrm{C}$ under $\mathrm{O}_{2}$ stream for $2 \mathrm{~h}$. After the thermal oxidation, the $\mathrm{ZnS}$ peaks have disappeared in $\mathrm{X}$-ray diffraction (XRD) but predominant (0002) and (004) peaks were obtained for the corresponding wurtzite and zincblende $\mathrm{ZnO}$ layers.

Yoo et al. ${ }^{15}$ tried to grow zincblende $\mathrm{ZnO}$ thin layers by thermal oxidation of $\mathrm{ZnS}$ at the substrate temperature of $900{ }^{\circ} \mathrm{C}$. It has been reported that the higher the substrate temperature, the better is the crystalline quality of $\mathrm{ZnO}$ layers. In order to obtain $\mathrm{ZnO}$ layers, $400 \mathrm{~nm}$ thick $\mathrm{ZnS}$ layers were grown on $\mathrm{Si}(001)$ substrates by PLD using a KrF excimer laser $(\lambda=248 \mathrm{~nm}, 10 \mathrm{~Hz})$. A polycrystalline $\mathrm{ZnS}$ target $(99.99 \%)$ was ablated for $1 \mathrm{~h}$ at a typical laser fluence of $5 \mathrm{~J} / \mathrm{cm}^{2}$. The ZnS growth temperature was varied from 200 to $700{ }^{\circ} \mathrm{C}$ under the same base pressure. Unfortunately, in these experimental studies, no evidences for zincblende $\mathrm{ZnO}$ growth were found.

\section{Sol-gel system}

Kim et al. ${ }^{16}$ used zinc acetate (Ac) 2-hydrate $\left[\mathrm{Zn}\left(\mathrm{CH}_{3} \mathrm{COO}\right)_{2}-2 \mathrm{H}_{2} \mathrm{O}\right]$ as the starting material for the growth of $\mathrm{ZnO}$ thin layers by the sol-gel process. The chemical reactions for $\mathrm{Zn}$ in this process were as follows: $\mathrm{Zn}\left(\mathrm{CH}_{3} \mathrm{CO}_{2}\right)_{2} 2 \mathrm{H}_{2} \mathrm{O} \rightarrow \mathrm{Zn}\left(\mathrm{CH}_{3} \mathrm{CO}_{2}\right)_{2}, \quad \mathrm{Zn}(\mathrm{Ac})_{2}+2 \mathrm{OR}-\mathrm{OH}$ $\rightarrow \mathrm{Zn}(\mathrm{OR})_{2}+2 \mathrm{Ac}-\mathrm{OH}$ (solvent was 2-methoxyethanol), and $\mathrm{Zn}(\mathrm{OR})_{2}+2 \mathrm{H}_{2} \mathrm{O} \rightarrow \mathrm{Zn}(\mathrm{OH})_{2}+2 R-\mathrm{OH}$. Then the $\mathrm{ZnO}$ preparation solution was used as $\mathrm{Zn}(\mathrm{OH})_{2} \rightarrow \mathrm{ZnO}+\mathrm{H}_{2} \mathrm{O}$. The $\mathrm{ZnO}$ thin films were prepared on $\mathrm{Pt}(111) / \mathrm{Ti} / \mathrm{SiO}_{2} / \mathrm{Si}(100)$ multilayered substrates by repeated sol-gel deposition process. The precursors were preheated at $300{ }^{\circ} \mathrm{C}$ for $10 \mathrm{~min}$ in an $\mathrm{O}_{2}$ ambient at atmospheric pressure. Finally, $\mathrm{ZnO}$ thin films were treated in the substrate temperature range of 400-800 ${ }^{\circ} \mathrm{C}$ for $1 \mathrm{~h}$ in an $\mathrm{O}_{2}$ atmosphere. The crystalline phase and crystal orientation of $\mathrm{ZnO}$ thin layers were determined by XRD.

In the above experiments, $\mathrm{GaAs}(001), \mathrm{Al}_{2} \mathrm{O}_{3}(0001)$, and $\mathrm{Pt}(111) / \mathrm{Ti} / \mathrm{SiO}_{2} / \mathrm{Si}(100)$ substrates have been used with a common $\mathrm{ZnS}$ buffer/interlayers for the growth of zincblende $\mathrm{ZnO}$ thin films. The zincblende $\mathrm{ZnS}$ thin layers favor to grow zincblende $\mathrm{ZnO}$ layers either by direct deposition or by thermal oxidation processes. However, thermal oxidation processes may not be a viable growth process for the zincblende $\mathrm{ZnO}$ epitaxy as thermal kinetics favor to relax with stable wurtzite structure even in the zincblende matrix. It has been reported that the maximum solid solubility of $\mathrm{O}$ in cubic $\mathrm{ZnS}$ 


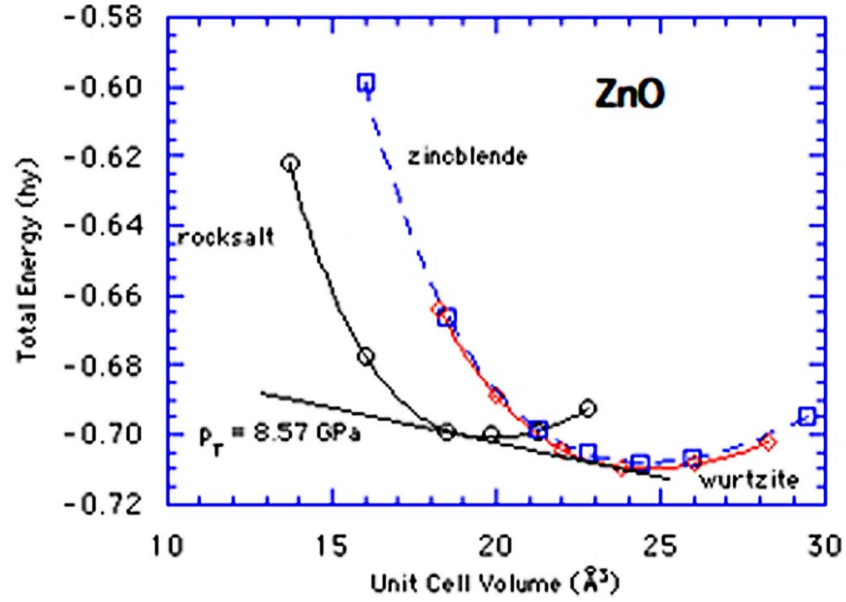

FIG. 5. (Color online) Total energy vs volume for the three phases of $\mathrm{ZnO}$ material. The zero of energy is the sum of the total energies of an isolated $\mathrm{Zn}$ and an isolated $\mathrm{O}$ atom. Reprinted with permission from Ref. 17(a). Copyright 2003 American Physical Society.

is $0.7 \mathrm{wt} \%(0.84 \mathrm{~mol} \%){ }^{7}$ Therefore, by thermal oxidation, it is impossible to grow single crystalline zincblende $\mathrm{ZnO}$ layers by complete oxidation of $\mathrm{ZnS}$ matrix-resulting in polytypism. In addition, it is expected that neutral radicals in $\mathrm{O}_{2}$ plasma species, the radicals that lead to no surface damage and/or defects, are important for growth of zincblende $\mathrm{ZnO}$ layers. ${ }^{13}$ Nonequilibrium growth techniques such as molecular-beam epitaxy may be suitable for the growth of metastable $\mathrm{ZnO}$ epitaxial layers. Further work is necessary, however, to explore the suitability of various techniques to obtain metastable zincblende $\mathrm{ZnO}$ epilayers.

\section{STRUCTURAL PROPERTIES}

Most of the II-O binary compound semiconductors crystallize either in zincblende or in wurtzite structures, where each anion is surrounded by four cations at the corners of a tetrahedron, and vice versa. The basic crystal structures of $\mathrm{ZnO}$ material are wurtzite and zincblende, as represented schematically in Fig. 2. At the ambient conditions, the thermodynamically stable $\mathrm{ZnO}$ phase is wurtzite. The counterpart on the other hand, the zincblende $\mathrm{ZnO}$ structures can also be stabilized by epitaxial growth on zincblende substrates that have been addressed in this section considering the experimental and theoretical evidences. $5,13,17$

\section{A. Phase stability of $\mathrm{ZnO}$}

\section{Theoretical studies}

Theoretically it is found that the $\mathrm{ZnO}$ material is stable with metastable zincblende phase. ${ }^{5,17}$ For these studies, the total energy of the $\mathrm{ZnO}$ material has been considered theoretically for the wurtzite, zincblende, and rocksalt phases as a function of unit cell volume, plotted in Fig. $5^{5,17}$ It is clear from the figure that the total energy of wurtzite $\mathrm{ZnO}$ is lower than that of the zincblende phase by $50 \mathrm{meV}$, indicating the possibility of obtaining metastable zincblende $\mathrm{ZnO}$. Using the first principles calculations, the zincblende $\mathrm{ZnO}$ lattice constant has been calculated to be in the range of 4.58-4.62 $\AA$, shown in Table II. In these theoretical calcula-
TABLE II. The lattice constant and bandgap energy of zincblende $\mathrm{ZnO}$ material calculated theoretically and/or estimated experimentally are summarized. The bandgap energy values are for room temperature.

\begin{tabular}{lcc}
\hline \hline$a(\AA)$ & $E(\mathrm{RT})(\mathrm{eV})$ & Ref. \\
\hline 4.58 & 0.87 & 18 \\
4.47 & 3.27 & 13 \\
4.595 & 3.28 & 16 \\
4.60 & $\cdots$ & 17 \\
4.18 & 3.22 and 3.12 & 14 \\
$\ldots$ & 3.26 & 15 \\
4.62 & 3.59 & 34 \\
4.62 & 1.486 & 17 \\
4.569 & $\ldots$ & 17 \\
4.47 & 3.27 & 25 \\
\hline \hline
\end{tabular}

tions, the energy difference between the wurtzite and zincblende phases $\left(\Delta E_{\mathrm{WZ}-\mathrm{ZB}}\right)$ has been estimated in the range of $50-150 \mathrm{meV} / \mathrm{atom}$. It has also been reported that the metastable zincblende $\mathrm{ZnO}$ phase is more covalent than the wurtzite phase ${ }^{5,18}$ since the Mullikan effective charge for $\mathrm{Zn}$ in wurtzite $\mathrm{ZnO}$ is estimated to be $0.82 e$, while it is $0.81 e$ for the zincblende $\mathrm{ZnO}$ structure. In addition, the calculated dielectric constant for the zincblende $\mathrm{ZnO}$ is 6.0 compared with 4.7 for the wurtzite $\mathrm{ZnO}$ phase. ${ }^{18} \mathrm{~A}$ larger dielectric constant suggests a larger refractive index of 2.49 (refractive index of wurtzite phase is 2.0), and a higher optical density for the zincblende phase may have special applications in certain optical devices such as photonic crystals.

\section{Experimental results}

Although the metastable zincblende $\mathrm{ZnO}$ phase is stable theoretically, to date, a few works have been demonstrated with epitaxial growth of zincblende $\mathrm{ZnO}$ layers. Ashrafi et $a l{ }^{13}$ have demonstrated the epitaxial growth of zincblende $\mathrm{ZnO}$ thin layers on $\mathrm{GaAs}(001)$ substrates. The zincblende $\mathrm{ZnS}$ thin buffer layers work as nucleation sites for the zincblende $\mathrm{ZnO}$ epitaxy as well as reduce the lattice mismatch in the $\mathrm{ZnO} / \mathrm{GaAs}$ heterostructure by $\sim 5 \% .{ }^{13}$ Figure 6 shows (a) a cross-sectional transmission electron microscopy (TEM) image and (b) a high-resolution TEM lattice image of $\mathrm{ZnO} / \mathrm{ZnS}$ heterointerface with the electron beam aligned along the $[1 \overline{1} 0]_{\mathrm{ZnS}}$, where the grain boundaries are clearly visible. A clear columnar growth mode is a common feature of cubic phase materials observed even in the zincblende GaN epitaxy. ${ }^{19}$ Although there are misfit dislocations at the $\mathrm{ZnO} / \mathrm{ZnS}$ heterointerfaces as indicated by arrows, it clearly illustrates the epitaxial relationships between the two layers that have been confirmed by XRD and selected area electron diffraction (SAED) pattern to be $[110]_{\mathrm{ZnO}} \|[110]_{\mathrm{ZnS}}$ and $[1 \overline{10}]_{\mathrm{ZnO}} \|[1 \overline{1} 0]_{\mathrm{ZnS}}{ }^{13}$ The SAED examination showed that the $\mathrm{ZnO}$ layers are tetragonally distorted with a partially relaxed lattice constant of $4.47 \AA$. This experimental lattice constant of zincblende $\mathrm{ZnO}$ is in the range of calculated lattice constants, shown in Table II. We believe that a smaller experimental lattice constant of zincblende $\mathrm{ZnO}$ is the result of partial relaxation of strain in the $\mathrm{ZnO} / \mathrm{ZnS} / \mathrm{GaAs}$ material system. 

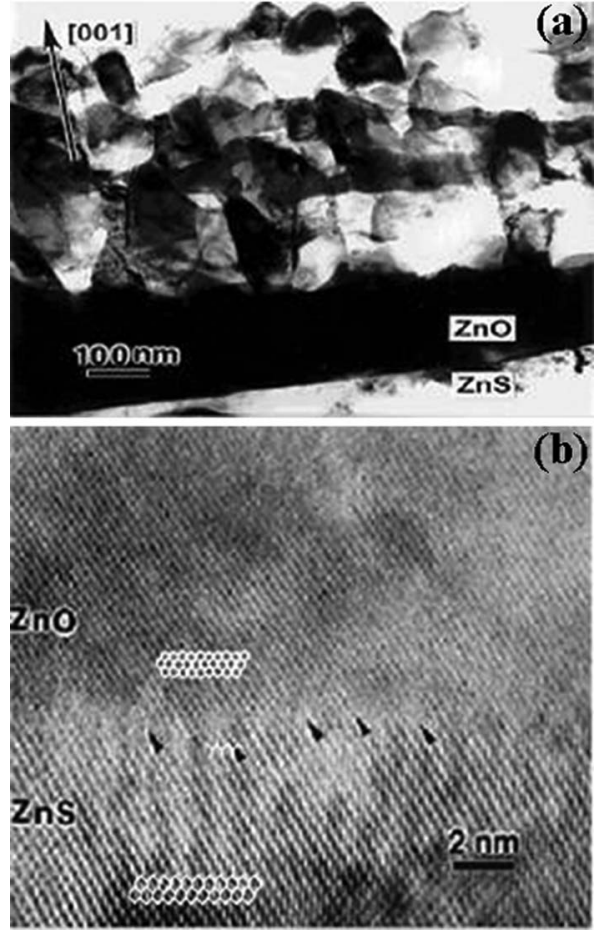

FIG. 6. TEM images of (a) cross section with columnar growth mode and (b) high-resolution lattice image of $\mathrm{ZnO} / \mathrm{ZnS}$ heterointerface grown on GaAs substrate. The SAED showed the partially relaxed lattice constant for zincblende $\mathrm{ZnO}$ to be $4.47 \AA$.

Since the zincblende $\mathrm{ZnO}$ is a metastable phase, there is a strong possibility to have a certain amount of wurtzite subdomains embedded in the zincblende matrix. However, there is no report yet on how to minimize the wurtzite subdomains in the zincblende $\mathrm{ZnO}$ matrix. In principle, these subdomain growths lead to columnar and hexagonal crystallites in surface morphology, observed also in the $\mathrm{GaN}$ material. Figures 7(a)-7(d) show the columnar and hexagonal crystallites of $\mathrm{ZnO}$ with the size of $30-50 \mathrm{~nm}$, taken from Ref. 16. Considering the crystallite sizes and structures, it is suggested that the hexagonal and columnar structures typically symbolize the $c$ axis oriented wurtzite and zincblende grains, respectively. The same surface morphology was also observed in the $\mathrm{ZnO}$ layers grown on $\mathrm{ZnS} / \mathrm{Al}_{2} \mathrm{O}_{3}$ substrates. ${ }^{13}$

However, for the annealing temperatures $\geqslant 700{ }^{\circ} \mathrm{C}$, the hexagonal-shaped grains have completely disappeared in the $\mathrm{ZnO} / \mathrm{Pt}(111) / \mathrm{Ti} / \mathrm{SiO}_{2} / \mathrm{Si}(100)$ heterostructure, as shown in Figs. $7(\mathrm{c})$ and $7(\mathrm{~d}){ }^{16}$ From the XRD peak broadening using Scherrer formula, it has been concluded that the grain size of $\mathrm{ZnO}$ at annealing temperatures above $700{ }^{\circ} \mathrm{C}$ does not increase similar to those below $600{ }^{\circ} \mathrm{C}$, dominated by wurtzite grains. This suggests that the postgrowth annealing may lead to elimination of the complex matrix in the zincblende $\mathrm{ZnO}$ layers. However, this affirmation needs further studies and annealing temperature and other growth parameters need to be optimized to obtain the single crystalline zincblende $\mathrm{ZnO}$ epilayers.

The zincblende $\mathrm{ZnO}$ layers grown on $\mathrm{ZnS} / \mathrm{GaAs}$ substrates also showed an entirely different surface morphology from that normally observed in the wurtzite $\mathrm{ZnO}$ thin layers. ${ }^{13,20}$ The surface root-mean-square $(\mathrm{rms})$ roughness of
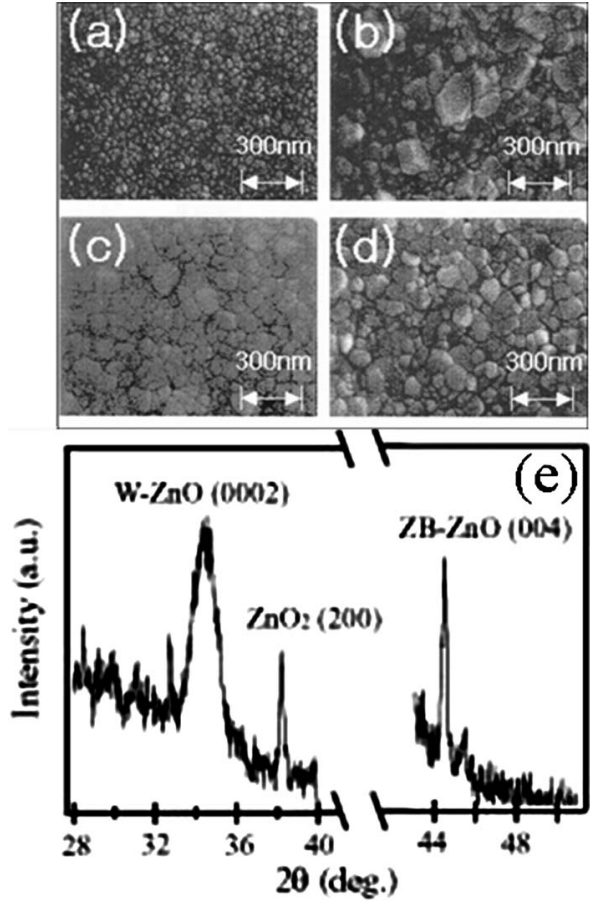

FIG. 7. The scanning electron micrographs of the surfaces of the $\mathrm{ZnO}$ thin films grown on $\mathrm{Pt}(111) / \mathrm{Ti} / \mathrm{SiO}_{2} / \mathrm{Si}$ substrates and annealed at (a) 500, (b) 600 , (c) 700 , and (d) $800{ }^{\circ} \mathrm{C}$, and (e) the XRD pattern of $\mathrm{ZnO}$ thin layers grown on $\mathrm{ZnS} / \mathrm{Al}_{2} \mathrm{O}_{3}$ substrates. For the annealing temperature $\geqslant 700{ }^{\circ} \mathrm{C}$, no hexagonal crystallites were observed. Reprinted with permission from Refs. 16 and 14. Copyrights 1993 American Institute of Physics and 2005 Elsevier, respectively.

the zincblende $\mathrm{ZnO}$ layers is suppressed drastically due to the decrease of the growth rate. The rms roughness of $\mathrm{ZnO}$ layers had a minimum of $1 \mathrm{~nm}$ for the growth rate of $0.30 \mu \mathrm{m} / \mathrm{h}$ with the best crystalline quality demonstrated in Ref. 21. Consistent with the hypothesis that the smoothness of the substrate is a key factor for nucleation of the cubic phase and its subsequent growth, this otherwise leads to an increase of the wurtzite/zincblende phase ratio or polytypism. ${ }^{7,21}$

To check these dominant grain growths in the $\mathrm{ZnO}$ epitaxy, Lee et al. ${ }^{14}$ have grown $\mathrm{ZnO}$ epitaxial layers on $\mathrm{ZnS} / \mathrm{Al}_{2} \mathrm{O}_{3}$ substrates with a $\mathrm{ZnS}$ layer thickness of $\sim 3 \mathrm{~nm}$. After the thermal oxidation, $\mathrm{ZnS}$ peaks completely disappeared in XRD measurements and predominant (0002) and (004) peaks were observed for the wurtzite and zincblende $\mathrm{ZnO}$ phases, respectively. Figure 7(e) shows the two dominant diffraction peaks of (0002) for wurtzite and (004) for zincblende structures by indicating the phase mixture of wurtzite and zincblende matrices. From these XRD results, the $\mathrm{ZnO}$ lattice constant has been estimated to be $4.18 \AA$ based on the data from Ref. 14.

Yoo et al. ${ }^{15}$ have also tried to grow zincblende $\mathrm{ZnO}$ material by oxidizing the zincblende $\mathrm{ZnS}$ thin layers grown on $\mathrm{Si}(100)$ substrates. Unfortunately, no evidences of zincblende $\mathrm{ZnO}$ were found in their XRD examination. It has been attributed that if the $\mathrm{S}$ sites are replaced by the $\mathrm{O}$ atoms in $\mathrm{ZnS}$ by thermal annealing, the structure of $\mathrm{ZnO}$ should be zincblende. However, it has been assumed that the $\mathrm{O}$ atoms diffuse into the $\mathrm{ZnS}$ matrix via interstitial sites and bond to 
$\mathrm{Zn}$, forcing $\mathrm{S}$ atoms to reside in the interstitial sites in turn, leading to a modification of the tetrahedral unit network. In addition, due to the small unit cell of $\mathrm{ZnO}$ compared to that of the $\mathrm{ZnS}$, some vacant spaces may be created which also could lead to the $\mathrm{ZnO}$ matrix to relax and finally, the more stable wurtzite structure was formed.

\section{B. Lattice constant}

Normally the lattice parameters of any crystalline material are calculated by Bragg's law by using a set of symmetrical and asymmetrical reflections. The lattice parameter of a compound semiconducting material usually depends on the following factors: ${ }^{22}$ (i) free-electron concentration acting via deformation potential, (ii) concentration of foreign atoms and defects, (iii) strain, and (iv) temperature.

For the zincblende $\mathrm{ZnO}$ epitaxy, the calculated lattice constant based on a modern $a b$ initio technique is predicted in the range of $4.58-4.62 \AA$, while experimentally, it is found to be $4.18 \AA$ (Ref. 14) and $4.47 \AA$ (Ref. 13). Table II shows a comparison of lattice parameters reported by the several groups for the $\mathrm{ZnO}$ material crystallized in zincblende phase. It is clear that the experimental lattice constant is less than the theoretical values because of the strain kinetics that are still active in the thin films since the lattice mismatch of $\sim 13 \%$ in the $\mathrm{ZnO} / \mathrm{ZnS}$ heterostructure is quite high. Therefore, critical studies are necessary for the growth of single crystalline zincblende $\mathrm{ZnO}$ layers, possibly on the nearly lattice-matched zincblende substrates, say $3 C$-SiC that has been discussed in Sec. VI.

\section{Polytypism in $\mathrm{ZnO}$}

Normally, it is extremely difficult to control the metastable zincblende phase of $\mathrm{ZnO}$ due to a tendency to form wurtzite subdomains within the zincblende matrix. Polytypism in metastable phases is a common problem that obstructs the realization of single crystalline metastable materials, such as zincblende $\mathrm{ZnO}$ epitaxy. It has been demonstrated that the $\mathrm{ZnO}(111)$-aligned stacking faults, lead to the formation of wurtzite micrograins that has also been observed in the cubic GaN layers grown on GaAs substrates. ${ }^{23,24}$ However, we believe that the polytypism in $\mathrm{ZnO}$ appeared in the $\mathrm{ZnO} / \mathrm{ZnS}$ heterostructures due to the two main reasons: (i) larger lattice misfits and (ii) complex interface geometry.

Figure 8(a) shows the reflection high-energy electron diffraction (RHEED) pattern observed from the zincblende $\mathrm{ZnO}$ layers grown on the $\mathrm{ZnS} / \mathrm{GaAs}$ substrates. ${ }^{13}$ The corresponding schematic of the RHEED pattern with open circles is shown in Fig. 8(b), together with the real structure of zincblende with closed circles. These reveal that the RHEED spots are distorted in-plane and out-of-plane lattice spacings resulting in an asymmetric pattern-which are also observed in the SAED patterns by TEM. The intensity of these spots for the higher orders is found to be relatively dimmer, which could suggest the presence of polytypism. Therefore, polytypism has been attributed to the presence of a small amount of wurtzite subdomains incorporated in the zincblende matrix via defects and/or complex interface oriented misalignment of atoms. ${ }^{13,25}$
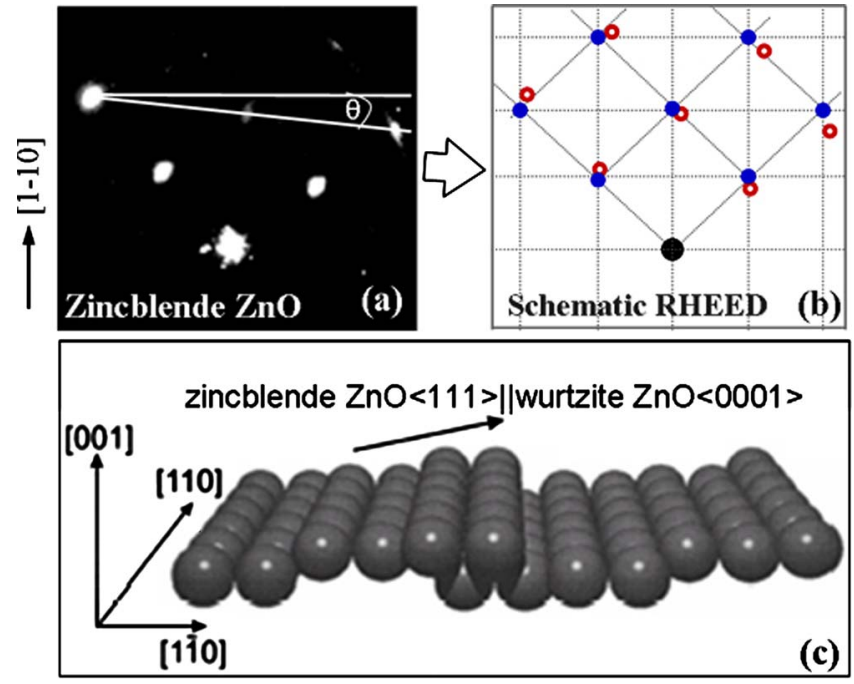

FIG. 8. (Color online) (a) Asymmetric RHEED pattern of $\mathrm{ZnO}$ layer with the (b) corresponding schematic with distortion in patterns. Assuming a parallel orientation of the hexagonal $c$ axis with respect to the cubic (111) direction, the growing (001)ZnO surface forms a "roof-tile"-like surface profile, as sketched in (c).

On the basis of these experimental evidences, the atomic arrangement of these adjacent zincblende and wurtzite phases is represented with the schematic in Fig. 8(c). It shows that the wurtzite planes closest in orientation to the (001) zincblende planes are of the (10-11) type, slightly tilted with respect to the zincblende (001) planes. As a result of this tensile strain in the $\mathrm{ZnO} / \mathrm{ZnS}$ heterostructure, an anomalous increase of the in-plane lattice spacing is expected, eventually followed by plastic relaxation of the built-in strain through the dislocation formation at the cubic-hexagonal boundary, consistent with the RHEED observations. ${ }^{13}$ Therefore, the (111) facets appearing during the three dimensional nucleation of $\mathrm{ZnO}$ layers on the $\mathrm{ZnS}$ surfaces, as experimentally observed, should act as preferential nucleation sites of the hexagonal matrix. We propose that the tensile strain kinetics and complex interface in the $\mathrm{ZnO} / \mathrm{ZnS}$ heterostructure could be related to the presence of defective regions with a hexagonal structure during the nucleation of zincblende $\mathrm{ZnO}$ layers.

\section{OPTICAL PROPERTIES}

The band structure as well as the bandgap energy of a zincblende $\mathrm{ZnO}$ is still under debate since a few reports appeared in the literature. A simple but a meaningful zincblende $\mathrm{ZnO}$ schematic band structure is represented, together with the wurtzite structure in Fig. 4. In this section, we will focus on optical properties of zincblende $\mathrm{ZnO}$ layers demonstrated in the literatures, and finally, we have compared those results with the stable wurtzite $\mathrm{ZnO}$ layers.

\section{A. Far- and near-field photoluminescences}

Yoo et al. ${ }^{15}$ have obtained the strong near-bandedge emission with the energy of $3.26 \mathrm{eV}$ at RT, which is very close to the zincblende $\mathrm{ZnO}$ bandgap energy reported by Kumano and co-workers ${ }^{25}$ It is interesting to note that the $\mathrm{x}$-ray measurements in Ref. 15 did not show any zincblende 

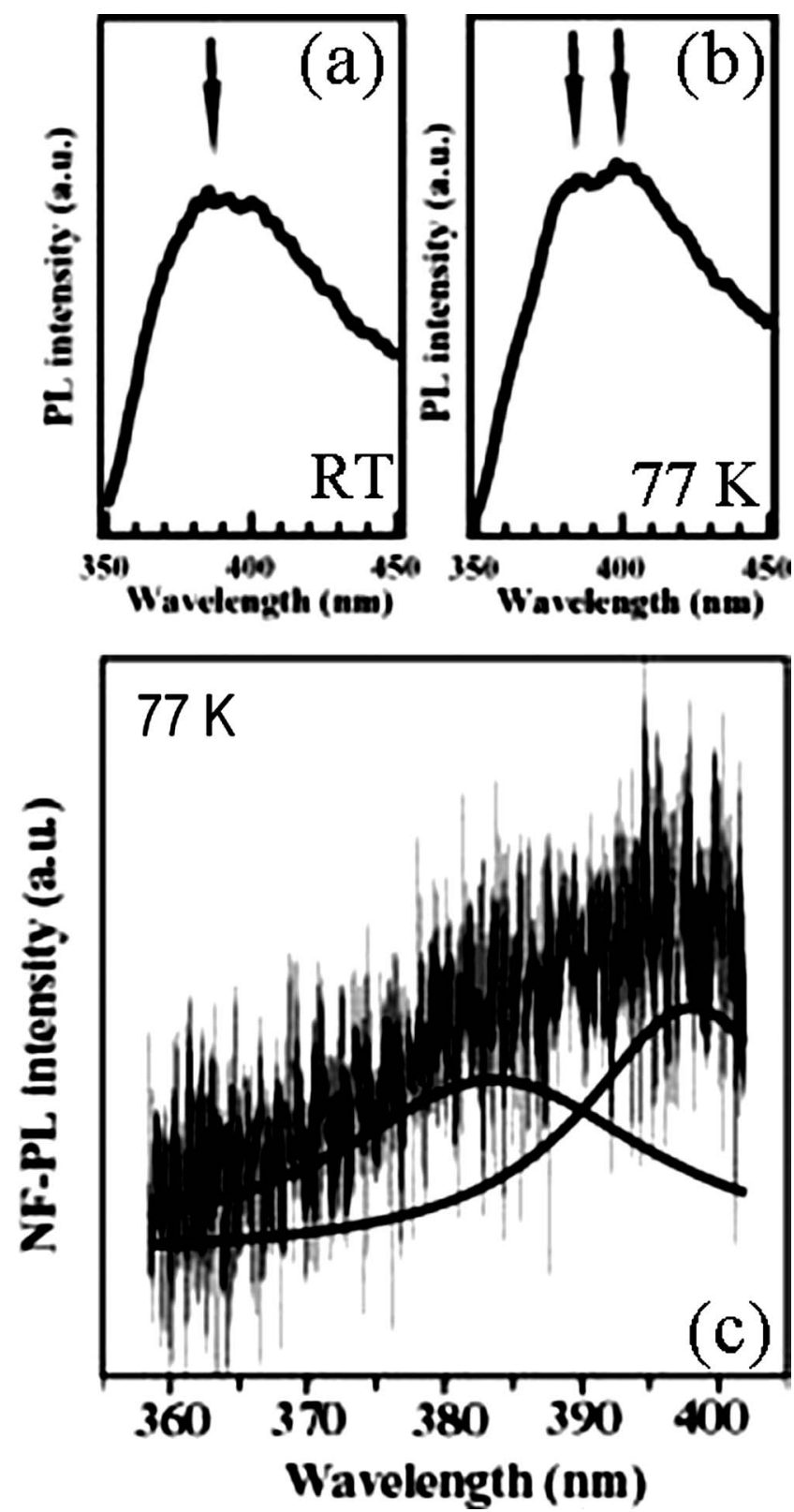

FIG. 9. [(a) and (b)] Far-field PL spectra of $\mathrm{ZnO}$ layers obtained by thermal oxidation of zincblende $\mathrm{ZnS}$ thin layers grown on $\mathrm{Al}_{2} \mathrm{O}_{3}$ substrate, and (c) the near-field PL spectrum measured at $77 \mathrm{~K}$. Reprinted with permission from Ref. 14. Copyright 2005 Elsevier.

$\mathrm{ZnO}$ peak, despite optical measurements showing bandedge emission close to the predicted bandgap of zincblende $\mathrm{ZnO}$ layers. Figures 9(a) and 9(b) show the far-field photoluminescence (PL) spectra of $\mathrm{ZnO}$ thin layers performed at RT and $77 \mathrm{~K}$, respectively, taken from Ref. 14. Only one dominant peak with its energy of $3.17 \mathrm{eV}$ was observed at RT, while two peaks with energies of 3.22 and $3.12 \mathrm{eV}$ were obtained at $77 \mathrm{~K}$ with the energy difference of $\sim 100 \mathrm{meV}$. To exclude the spectral broadening in the far-field PL measurements due to size fluctuation of nanocrystallites, nearfield PL spectroscopy was performed at $77 \mathrm{~K}$ with higher spatial and spectral resolutions, as shown in Fig. 9(c). A clear and distinct two dominant peaks with the energies of 3.22 and $3.12 \mathrm{eV}$ were observed in the near-field PL spectrum with the same energy difference of $\sim 100 \mathrm{meV}$. This energy

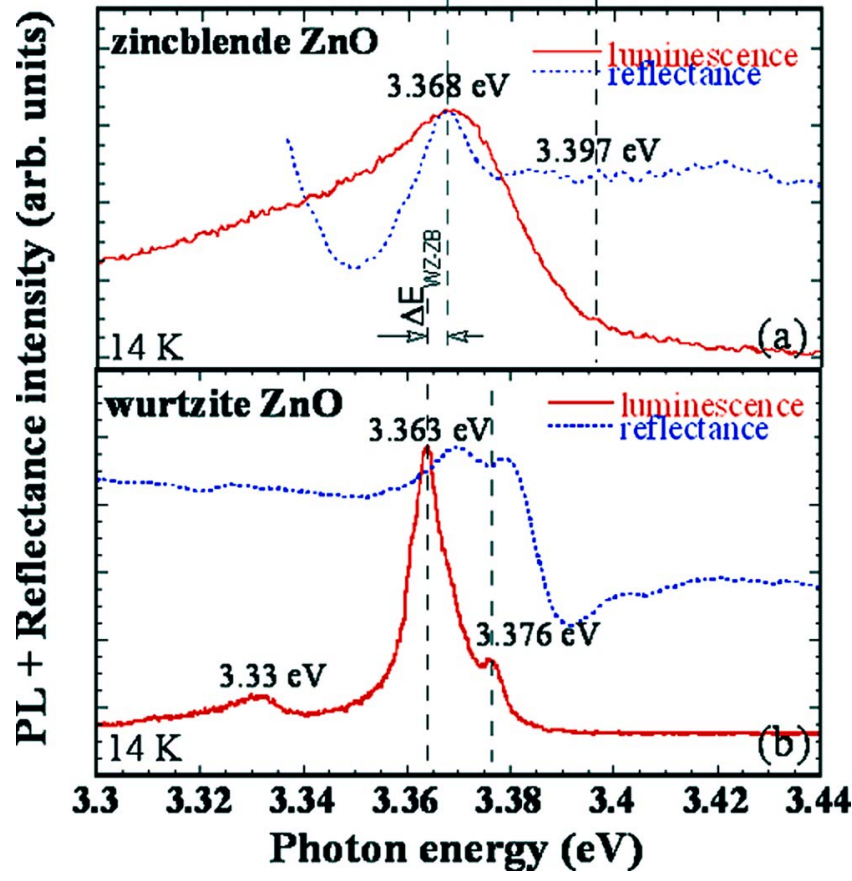

FIG. 10. (Color online) PL and reflectance spectra of (a) zincblende and (b) wurtzite $\mathrm{ZnO}$ layers grown on $\mathrm{ZnS} / \mathrm{GaAs}$ and $\mathrm{Al}_{2} \mathrm{O}_{3}$ substrates, respectively. The experiments were preformed at $14 \mathrm{~K}$ using the $\mathrm{He}-\mathrm{Cd}$ laser for the excitation wavelength of $325 \mathrm{~nm}$.

difference is slightly larger than the theoretically calculated energy difference in between wurtzite and zincblende $\mathrm{ZnO}$ phases of $\sim 80 \mathrm{meV}^{26}$

In addition, the intensity of zincblende $\mathrm{ZnO}$ peak with lower energy is stronger than that of the wurtzite structure, and the emission with higher energy is assigned to be wurtzite structure, shown in Fig. 9(c). The difference in emission intensity means the difference of exciton density because the exciton density depends on the crystal orientation. ${ }^{22,25}$ However, these two broad peaks with different intensities observed in PL spectra from the same $\mathrm{ZnO}$ sample should be interpreted with care, although there is a big energy difference of $100 \mathrm{meV}$. In principle, carriers populate and relax to lower band from the upper band, say wurtzite to zincblende phase since wurtzite phase has a higher bandgap energy. In these materials, therefore, PL emission should be predominantly from the lower energy structures, say zincblende $\mathrm{ZnO}$ layers, and distinction should be difficult. Therefore, we believe that to get in-depth insights from these $\mathrm{ZnO}$ structural phases, further studies are necessary.

\section{B. Comparative studies of luminescence}

The discrepancies discussed above in optical properties have been clarified by PL and reflectance measurements, plotted in Fig. 10. The zincblende and wurtzite $\mathrm{ZnO}$ layers were grown on $\mathrm{ZnS} / \mathrm{GaAs}$ and $6 \mathrm{H}$-SiC substrates, respectively. Figures 10(a) and 10(b) show the corresponding PL and reflectance spectra of zincblende and wurtzite $\mathrm{ZnO}$ layers performed at $14 \mathrm{~K}$. It is very clear from the spectra that the PL peak energies are coincident with the reflectance peak energies for both the zincblende and wurtzite $\mathrm{ZnO}$ layers. In wurtzite $\mathrm{ZnO}$ layers, the dominant peaks were observed at 
$3.385,3.378$, and $3.364 \mathrm{eV}$ that have been assigned to be free $B$ and $A$ excitons and neutral donor-bound exciton $\left(D^{0} X\right)$ emission, respectively. ${ }^{27}$ On the other hand, in zincblende $\mathrm{ZnO}$ epilayers, the dominant peak energy was observed at $3.368 \mathrm{eV}$. It is noted that the detected PL peak energy at $3.368 \mathrm{eV}$ in zincblende $\mathrm{ZnO}$ layers is very strong and dominant all throughout the experiments. PL excitation experiments on these zincblende $\mathrm{ZnO}$ samples by the authors (not shown) revealed three peaks at 3.417, 3.382, and $3.368 \mathrm{eV}^{25}$ The peak energy positions of 3.382 and $3.417 \mathrm{eV}$ are very close to the $B$ and $C$ exciton transition energies in the wurtzite $\mathrm{ZnO}$ layers, respectively. ${ }^{22,27}$ On the other hand, the peak detected at $3.368 \mathrm{eV}$ is lower in energy than the theoretical prediction for the $A$ exciton energy of $3.3773 \mathrm{eV}$ and the experimental result of $3.389 \mathrm{eV}$ obtained from the wurtzite $\mathrm{ZnO}$ layers. ${ }^{22}$ The origin of this energy shift to the lower energy, therefore, is not clear at present but two possible candidates for explaining this effect are: (i) the strain-induced renormalization of energy bands due to the biaxial tensile stress possibly present in the $\mathrm{ZnO}$ film grown on the $\mathrm{ZnS}$ buffer layer and (ii) the change of the $\mathrm{ZnO}$ crystalline structure to the zincblende phase. However, to make clear this assertion and/or origin of this PL peak energy position in the zincblende $\mathrm{ZnO}$ layers, further studies are necessary. It is noted that the bandgap energy for the zincblende $\mathrm{ZnO}$ is estimated theoretically to be $3.59 \mathrm{eV},{ }^{28}$ which is higher than that of the experimentally observed bandgap of wurtzite $\mathrm{ZnO}$ layers. The higher bandgap energy in zincblende $\mathrm{ZnS}$ was predicted by theory, whereas experimentally observed $\mathrm{ZnS}$ bandgap energy is smaller for the zincblende phase when compared to wurtzite phase. It is worth noting that theoretical prediction of bandgap energy for various phases of $\mathrm{ZnO}$ and $\mathrm{ZnS}$ materials has been larger than experimental values. Zincblende GaN has also a lower bandgap energy compared to the wurtzite GaN layers, consistent with the $\mathrm{ZnS}$ and $\mathrm{ZnO}$ materials. ${ }^{23}$

From these experimental data, the Stokes shift in zincblende $\mathrm{ZnO}$ has been estimated to be $\sim 1 \mathrm{meV},{ }^{25}$ while it was $14 \mathrm{meV}$ for the wurtzite $\mathrm{ZnO}$ material. ${ }^{29}$ This negligible Stokes shift in the zincblende $\mathrm{ZnO}$ implies that the $\mathrm{ZnO}$ epilayer quality is very high, and the origin of the luminescence is mainly contributed from the free exciton transitions. These features strongly suggest that the contribution of impurities and/or defects to the optical transitions is negligible from low temperature up to RT. It is also expected that the emission stimulated by excitons in the zincblende structure may be stronger than that in the wurtzite structure since the piezoelectric field effect is absent in the zincblende structure that normally quenches the exciton energies in wurtzite phase.

Temperature-dependent PL measurements (not shown) for both the zincblende and wurtzite $\mathrm{ZnO}$ layers ${ }^{30}$ showed that the PL peak energies decrease gradually with the increase of temperature. From this result, the photon energy differences between the zincblende (near bandedge) and wurtzite $\left(E_{\mathrm{XA}}\right) \mathrm{ZnO}$ are found to be $\sim 15$ and $\sim 26 \mathrm{meV}$ at $4 \mathrm{~K}$ and RT, respectively. For the bandedge emission energy of wurtzite $\mathrm{ZnO}$ epilayers grown on the almost latticematched substrate $\left(\mathrm{ScAlMgO}_{4}\right)$, it has the value of $3.33 \mathrm{eV}$ at $\mathrm{RT},{ }^{20}$ whereas the bandgap energy of zincblende $\mathrm{ZnO}$ layers at RT has been found to be $3.27 \mathrm{eV}^{25}$ Therefore, the bandgap energy difference at RT in between wurtzite and zincblende phases of $\mathrm{ZnO}$ has been reported to be in the range of $60-100 \mathrm{meV}^{28}$ It is worth noting that theoretical calculations ${ }^{28}$ have predicted a bandgap energy difference of $80 \mathrm{meV}$ between the wurtzite and zincblende phases. In the case of GaN epitaxy for the wurtzite and zincblende structures, the energy difference has been reported to be $\sim 80 \mathrm{meV}^{23}$

\section{TRANSPORT PROPERTIES}

Hall-effect measurements are the most widely used technique to assess the transport properties of semiconducting materials. To study the electrical properties of $\mathrm{ZnO}$ layers, Hall measurements were performed at RT for the average layer thickness of $0.5-1 \mu \mathrm{m}$. Hall measurements over a wide temperature range provide quantitative information on impurities, imperfections, uniformity, scattering mechanisms, etc. The resistivity, carrier concentration, and Hall mobility of the thin films were measured using a standard van der Pauw geometry. Ohmic contacts were made using In. For these measurements, the applied magnetic field was set to $0.3 \mathrm{~T}$, and the numerical calculation was performed using a standard computer program.

The zincblende and wurtzite epitaxial $\mathrm{ZnO}$ layers grew normally with $n$-type, conductivity irrespective of the substrates and/or growth systems. This indicates that the asgrown $\mathrm{ZnO}$ layers are $n$-type, irrespective of their crystalline structures. This might be related to the $\mathrm{O}$ vacancy and/or $\mathrm{Zn}$ interstitials due to the nonstoichiometric growth conditions. Nakahara et al., Pearton et al., ${ }^{31}$ and Van de Walle and Neugebauer ${ }^{32}$ have suggested that $\mathrm{H}$ is responsible for the $n$-type conductivity in the $\mathrm{ZnO}$ material since the fact that $\mathrm{H}^{+}$is only stable in $\mathrm{ZnO}$ material implies that $\mathrm{H}$ acts as a shallow donor in $\mathrm{ZnO}$. In addition, $\mathrm{Ga}, \mathrm{Al}$, and $\mathrm{In}$ impurities in the $\mathrm{ZnO}$ epitaxial layers are known to be donors. ${ }^{32}$

\section{A. Carrier density}

To distinguish the structural discrepancies in zincblende $\mathrm{ZnO}$ thin layers, carrier concentrations of zincblende and wurtzite epitaxial $\mathrm{ZnO}$ layers, deposited on $\mathrm{ZnS} / \mathrm{GaAs}$ and $\mathrm{Al}_{2} \mathrm{O}_{3}$ substrates, respectively, have been plotted as a function of II/VI ratio in Fig. 11(a). It is noted that the zincblende $\mathrm{ZnO}$ layers were grown here by $\mathrm{H}_{2} \mathrm{O}$-assisted molecularbeam epitaxy, while wurtzite $\mathrm{ZnO}$ layers were grown with $\mathrm{O}_{2}$ plasma-assisted molecular-beam epitaxy. ${ }^{33}$ Figure 11(a) shows that the carrier concentrations of both $\mathrm{ZnO}$ layers are reducing with the increase of the II/VI flux ratios. However, there is a significant difference in carrier concentration variation with II/VI ratios in between zincblende and wurtzite $\mathrm{ZnO}$ layers. For the zincblende $\mathrm{ZnO}$ layers, the carrier concentration increases abruptly with the increase of II/VI flux ratio until the carrier concentration reaches a peak value at $\sim 10^{19} \mathrm{~cm}^{-3}$, while the zincblende $\mathrm{ZnO}$ carrier concentration starts to decrease with the increase of II/VI flux ratio, the wurtzite $\mathrm{ZnO}$ carrier concentration is maximum. It is very clear that the slopes of the decreasing carrier concentration in 

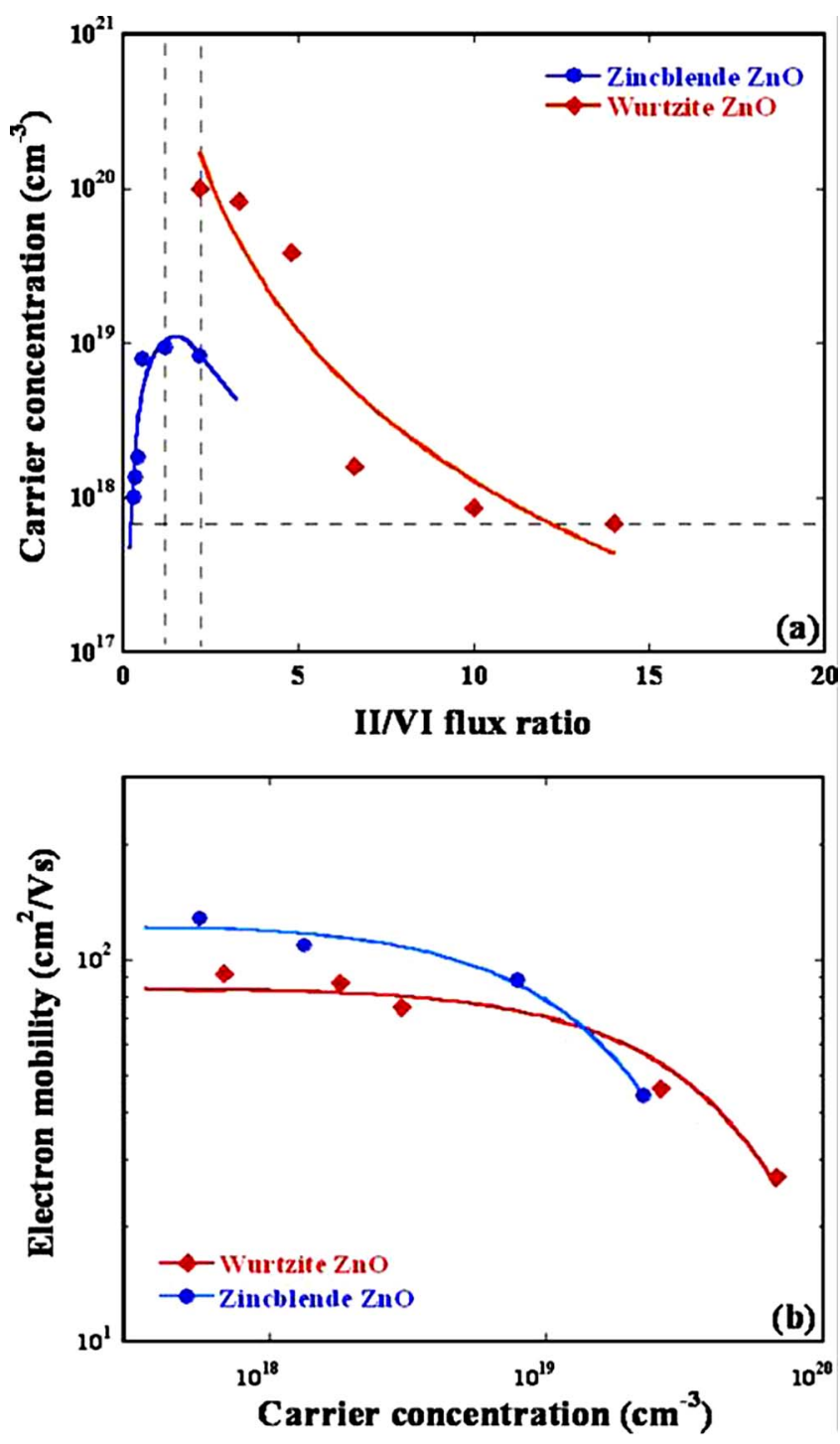

FIG. 11. (Color online) Transport properties of wurtzite and zincblende $\mathrm{ZnO}$ layers. (a) The carrier concentration as a function of II/VI flux ratio and (b) electron mobility as a function of carrier concentration have been plotted. The transport properties are obtained by using the Hall-effect measurements at room temperature. The $\mathrm{ZnO}$ layer thicknesses were in the range of $0.5-1 \mu \mathrm{m}$.

both materials are different, i.e., contributed kinetics in zincblende and wurtzite materials are different. The typical maximum carrier concentration for the zincblende $\mathrm{ZnO}$ is $\sim 10^{19} \mathrm{~cm}^{-3}$, while for the wurtzite $\mathrm{ZnO}$ is $\sim 10^{20} \mathrm{~cm}^{-3}$-an order of magnitude higher concentration in the wurtzite $\mathrm{ZnO}$ layers. This lower carrier concentration in zincblende $\mathrm{ZnO}$ has been attributed to the less contribution of impurities and/or higher structural symmetry than the wurtzite $\mathrm{ZnO}$ phase. In addition, the $\mathrm{Zn}$-rich $\mathrm{ZnO}$ layers have the better transport properties than the O-rich layers in both the material phases. This experimental result indicates that $p$-type doping in zincblende $\mathrm{ZnO}$ epitaxial layers may be more favorable over their wurtzite counterparts.

\section{B. Electron mobility}

To clarify the role of individual structures in transport properties, the electron mobilities of both the zincblende and wurtzite $\mathrm{ZnO}$ layers have been plotted as a function of carrier concentration in Fig. 11(b). It shows that the typical electron mobility of wurtzite $\mathrm{ZnO}$ is $\sim 90 \mathrm{~cm}^{2} / \mathrm{V} \mathrm{s}$ for the carrier concentration of $\sim 10^{18} \mathrm{~cm}^{-3}$. On the contrary, the zincblende $\mathrm{ZnO}$ shows the higher electron mobility to be $\sim 130 \mathrm{~cm}^{2} / \mathrm{V} \mathrm{s}$ for the same carrier concentration as that of the wurtzite structure. The electron mobility of the zincblende $\mathrm{ZnO}$ is relatively higher than that of the wurtzite structure. For the lower (higher) carrier concentration region, zincblende $\mathrm{ZnO}$ has the higher (lower) electron mobility than the wurtzite phase. Owing to the structural symmetry in zincblende $\mathrm{ZnO}$, the electron mobility should be higher but it seems that the electron mobility is limited by another factor. This is not clear at this moment but one candidate might be the rough surface morphology induced due to the roughness at the heterointerfaces. It has been demonstrated that the growth morphology also plays an important role in controlling the electron mobility. ${ }^{34}$ Additionally, Van de Walle and Neugebauer ${ }^{32}$ have demonstrated that $\mathrm{H}^{+}$serves as a doping source in the molecular-beam epitaxy and exclusively acts as a donor, which effectively modifies the optical and electrical properties as well.

As the carriers travel through a semiconductor, they encounter various scattering mechanisms that govern the carrier mobility in the electronic system. Usually, the carrier's mobility is limited by the electron-electron as well as electron-phonon scatterings. However, the electron-phonon scattering, together with the electron-impurity scattering rate in the zincblende phase, is lower than that of the wurtzite structure due to the effective lower density of states described by $n_{\mathrm{eff}}=2\left(2 \pi m_{e} k_{B} T / h^{2}\right)^{3 / 2} \cong 4 \times 10^{18} \mathrm{~cm}^{-3} .{ }^{35}$ This suggests a possibility to enhance high-field mobility in the zincblende structure in comparison with the wurtzite structure. In addition, the higher electron mobility in the zincblende $\mathrm{ZnO}$ structure than that of the wurtzite structure can be attributed to the highly symmetric properties such as weaker phonon scatterings and lower electron masses.

\section{CONCLUSION AND OUTLOOK}

The major difficulty in obtaining the single crystalline zincblende $\mathrm{ZnO}$ epilayers is the wurtzite subdomain grains in the cubic matrix resulting in the polytypism. In this complex lattice matrix, the experimental zincblende $\mathrm{ZnO}$ lattice constant has been estimated under the biaxial strain to be $4.47 \AA$, while the bandgap energy at RT is $3.27 \mathrm{eV}$. From this review, the estimated bandgap energy difference in between the wurtzite and the zincblende $\mathrm{ZnO}$ is found in the range of $60-100 \mathrm{meV}$, consistent with the theoretical calculations. For the transport properties, relatively lower carrier concentration with the higher electron mobility in the zincblende $\mathrm{ZnO}$ is obtained. These overall properties in zincblende $\mathrm{ZnO}$ are expected to contribute in solving the long standing problems, such as control of $p$-type conductivity and reduction of the spontaneous polarization.

However, to solve these long standing issues in the $\mathrm{ZnO}$ epitaxy, the metastable zincblende $\mathrm{ZnO}$ has to be single crystalline grown on closely lattice-matched substrates. Toward this goal, it is expected that the zincblende $\mathrm{ZnO}$ research will 


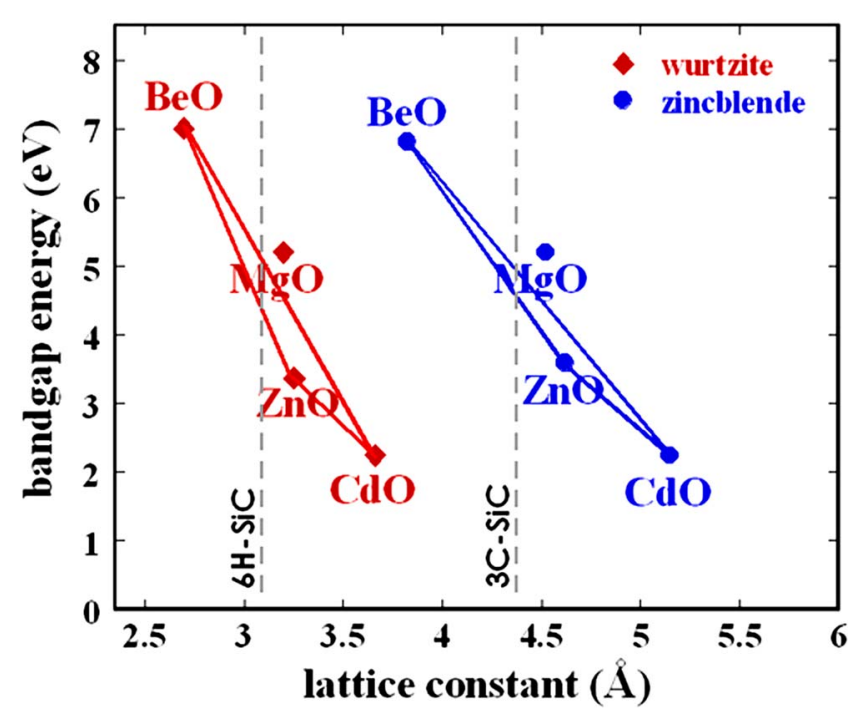

FIG. 12. (Color online) The bandgap energies and lattice constants are shown for the common II-O materials suitable for growth on $3 C$ - and $6 \mathrm{H}$-SiC substrates. The data of wurtzite and zincblende $\mathrm{MgO}, \mathrm{ZnO}$, and $\mathrm{CdO}$ materials are taken experimentally and/or theoretically from Refs. 13, 17 , and 36-38. This combination of II-O materials may be suitable for the optoelectronic devices based on the zincblende and wurtzite structures.

be focused on the use of $3 \mathrm{C}$-SiC substrate instead of the inter-buffer layer deposition on the zincblende substrates, e.g., GaAs. The $3 C$-SiC has a lattice constant of $4.36 \AA$, resulting in a lattice mismatch in the $\mathrm{ZnO} / 3 C$-SiC heterostructure of $\sim 2 \%$. From the viewpoint of biaxial strain mechanism induced by the lattice misfits in heterostructures, which governs, in principle, the overall crystalline, optical, and transport properties of materials, the $\mathrm{SiC}$ substrate will help us to explore the II-O materials leading to quantum structures in parallel to the III-N materials. By using this substrate, the polytypism will be minimized and the single crystalline zincblende $\mathrm{ZnO}$ epitaxial layers will be realized. Considering the experimental zincblende $\mathrm{ZnO}$ and $\mathrm{BeO}$ layers and theoretical $\mathrm{MgO}$ and $\mathrm{CdO}$ lattice constants, ${ }^{36-38}$ the II-O materials suitable for optoelectronic device applications based on $6 \mathrm{H}$-SiC and $3 \mathrm{C}$-SiC substrates are shown in Fig. 12. This proximity of lattice constants of II-O materials with widely available $\mathrm{SiC}$ substrates opens up an opportunity for developing blue and ultraviolet lasers and light emitting diodes.

\section{ACKNOWLEDGMENTS}

This research is supported in part by the Australian Research Council, Australia, Institute of Physical and Chemical Research (RIKEN), and the Ministry of Education, Science, Sports and Culture, Japan.

${ }^{1}$ R. J. Guerrero-Moreno and N. Takeuchi, Phys. Rev. B 66, 205205 (2002); K. J. Chang, S. Froyen, and M. L. Cohen, J. Phys. C 16, 3475 (1983).

${ }^{2}$ O. Madelung, Semiconductors: Physics of Nontetragonally Bonded Binary Compounds, Landolt-Bornstein, New Series, Group III, Vol. 17, Part B, edited by U. Rossler (Springer, Heidelberg, 1999), p. 22; U. Ozgur, Y. I. Alivov, C. Liu, A. Teke, S. Dogan, and H. Morkoc, J. Appl. Phys. 98, 41301 (2005); W. Gluck, Solid State Commun. 8, 1831 (1970).

${ }^{3}$ R. T. Sanderson, Chemical Bonds and Bond Energy, 2nd ed. (Academic, New York, 1976).

${ }^{4}$ C. Cheng, R. J. Needs, and V. Heine, J. Phys. C 21, 1049 (1988).
${ }^{5}$ M. Murayama and T. Nakayama, Phys. Rev. B 49, 4710 (1994); L. Zhang and H. Huang, Appl. Phys. Lett. 90, 023115 (2007).

${ }^{6}$ J. I. Pankove, Materials Research Society Symposia Proceedings (Materials Research Society, Pittsburgh, 1990), Vol. 162, p. 515; B. Daudin, G. Feuillet, J. Hubner, Y. Samson, F. Widmann, A. Philippe, C. BruChevallier, G. Guillot, E. Bustarret, G. Bentoumi, and A. Deneuville, J. Appl. Phys. 84, 2295 (1998).

${ }^{7}$ T. Kogure and Y. Bando, J. Electron Microsc. 47, 135 (1998); M. Posternak, A. Baldereschi, A. Catellani, and R. Resta, Phys. Rev. Lett. 64, 1777 (1990); I. Vurgaftman, J. R. Meyer, and L. R. Ram-Mohan, J. Appl. Phys. 89, 5815 (2001).

${ }^{8}$ R. Klann, O. Brandt, H. Yang, H. T. Grahn, and K. H. Ploog, Appl. Phys. Lett. 70, 1076 (1997).

${ }^{9}$ D. C. Reynolds, C. W. Litton, and T. C. Collins, Phys. Rev. A 140, 1726 (1965).

${ }^{10}$ D. G. Thomas, J. Phys. Chem. Solids 15, 86 (1960); J. J. Hopfield, ibid. 15, 97 (1960).

${ }^{11}$ C. Priester and M. Lannoo, Phys. Rev. B 44, 10559 (1991); S. Z. Karazhanov, P. Ravindran, A. Kjekshus, H. Fjellvag, U. Grossner, and B. G. Svensson, J. Appl. Phys. 100, 043709 (2006).

${ }^{12}$ F. M. Phelps III, M.I.T. Wavelength Tables (MIT Press, Cambridge, MA, 1982), Vol. 2.

${ }^{13}$ A. B. M. A. Ashrafi, A. Ueta, A. Avramescu, H. Kumano, and I. Suemune, Appl. Phys. Lett. 76, 550 (2000); A. B. M. A. Ashrafi, A. Ueta, H. Kumano, I. Suemune, Y.-W. Ok, and T.-Y. Seong, ibid. 79, 470 (2001); A. A. Ashrafi, A. Ueta, H. Kumano, and I. Suemune, J. Cryst. Growth 221, 435 (2000).

${ }^{14}$ G. H. Lee, T. Kawazoe, and M. Ohtsu, Appl. Surf. Sci. 239, 394 (2005). ${ }^{15}$ Y.-Z. Yoo, Y. Osaka, T. Fukumura, M. Kawasaki, H. Koinuma, T. Chikyow, P. Ahmet, A. Setoguchi, and S. F. Chichibu, Appl. Phys. Lett. 78, 616 (2001).

${ }^{16}$ S.-K. Kim, S.-Y. Jeong, and C.-R. Cho, Appl. Phys. Lett. 82, 562 (2003).

${ }^{17}$ (a) J. E. Jaffe and A. C. Hess, Phys. Rev. B 48, 7903 (1993); (b) J. E. Jaffe, J. A. Snyder, Z. Lin, and A. C. Hess, ibid. 62, 1660 (2000); (c) J. Uddin and G. E. Scuseria, ibid. 74, 245115 (2006); (d) A. Qteish, J. Phys.: Condens. Matter 12, 5639 (2000); (e) H. Baaziz, Z. Charifi, F. El Haj Hassan, S. J. Hashemifar, and H. Akbarzadeh, Phys. Status Solidi B 243, 1296 (2006); (f) W. H. Bragg and J. A. Darbyshire, J. Met. 6, 238 (1954); (g) X. W. Sun, Z. J. Liu, Q. F. Chen, H. W. Lu, T. Seong, and C. W. Wang, Solid State Commun. 140, 219 (2006).

${ }^{18}$ Z. X. Yu, C. Z. Wen, Q. Y. Peng, F. Yan, Z. Liang, Q. Li, M. M. Zhen, L. R. Ping, and W. W. Kui, Chem. Phys. Lett. 24, 1031 (2007).

${ }^{19}$ N. Kuwano, Y. Nagamoto, K. Kobayashi, K. Oki, S. Miyoshi, H. Yamaguchi, K. Onabe, and Y. Shiraki, Jpn. J. Appl. Phys., Part 1 33, 18 (1994).

${ }^{20}$ Z. K. Tang, G. K. L. Wong, P. Yu, M. Kawasaki, A. Ohtomo, H. Koinuma, and Y. Segawa, Appl. Phys. Lett. 72, 3270 (1998); A. B. M. A. Ashrafi, Y. Segawa, K. Shin, J. Yoo, and T. Yao, Appl. Surf. Sci. 249, 139 (2005).

${ }^{21}$ A. B. M. A. Ashrafi, I. Suemune, and H. Kumano, Jpn. J. Appl. Phys., Part 1 41, 2851 (2002); B. Daudin, G. Feuillet, J. Hubner, Y. Samson, F. Widmann, A. Philippe, C. Bru-Chevallier, G. Guillot, E. Bustarret, G. Bentoumi, and A. Deneuville, J. Appl. Phys. 84, 2295 (1998); A. B. M. A. Ashrafi, Y. Segawa, K. Shin, and T. Yao, ibid. 100, 063523 (2006).

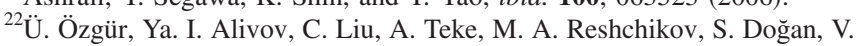
Avrutin, S.-J. Cho, and H. Morkoç, J. Appl. Phys. 98, 041301 (2005).

${ }^{23}$ B. Daudin, G. Feullet, J. Hunber, G. Bentoumi, and A. Deneuville, J. Appl. Phys. 84, 2295 (1998).

${ }^{24}$ D. Schikora, M. Hankeln, D. J. As, K. Lischka, T. Litz, A. Wagg, T. Buhrow, and F. Henneberger, Phys. Rev. B 54, R8381 (1996).

${ }^{25}$ H. Kumano, A. A. Ashrafi, A. Ueta, A. Avramescu, and I. Suemune, J. Cryst. Growth 214/215, 280 (2000); A. A. Ashrafi, A. Ueta, H. Kumano, and I. Suemune, ibid. 221, 435 (2000); I. Suemune, A. B. M. A. Ashrafi, M. Ebihara, M. Kurimoto, H. Kumano, T.-Y. Seong, B.-J. Kim, and Y.-W. Ok, Phys. Status Solidi B 241, 640 (2004).

${ }^{26}$ C. Yeh, S. Wei, and A. Zunger, Phys. Rev. B 50, 2715 (1994); S. Bloom and I. Orten Burger, Phys. Status Solidi B 57, 561 (1973).

${ }^{27}$ D. W. Hamby, D. A. Lucca, M. J. Kolpfstein, and G. Cantwell, J. Appl. Phys. 93, 3214 (2003); A. Teke, Ü. Özgür, S. Doğan, X. Gu, H. Morkoç, B. Nemeth, J. Nause, and H. O. Everitt, Phys. Rev. B 70, 195207 (2004). ${ }^{28}$ M. Oshikiri and F. Aryasetiawan, Phys. Rev. B 60, 10754 (1999).

${ }^{29}$ P. Zu, Z. K. Tang, G. K. L. Wong, M. Kawasaki, A. Ohtomo, H. Koinuma, and Y. Segawa, Solid State Commun. 103, 459 (1997).

${ }^{30}$ H. D. Sun, T. Makino, Y. Segawa, Z. K. Tang, G. K. L. Wong, M. Kawasaki, A. Ohtomo, K. Tamura, and H. Koinuma, Appl. Phys. Lett. 77, 4250 (2000); T. Makino, C. H. Chia, N. T. Turn, Y. Segawa, M. Kawasaki, 
A. Ohtomo, K. Tamura, and H. Koinuma, ibid. 76, 3549 (2000).

${ }^{31}$ K. Nakahara, H. Takasu, P. Fons, A. Yamada, K. Iwata, K. Matsubara, R Hunger, and S. Niki, Appl. Phys. Lett. 79, 4139 (2001); S. J. Pearton, D. P. Nortan, K. Ip, and Y. W. Heo, J. Vac. Sci. Technol. B 22, 932 (2004). ${ }^{32}$ C. Van de Walle and J. Neugebauer, Nature (London) 423, 626 (2003); ZnO Bulk, Thin Films, and Nanostructures: Processing, Properties, Applications, edited by C. Jagadish and S. J. Pearton (Elsevier, Oxford, 2006).

${ }^{33}$ A. B. M. A. Ashrafi, I. Suemune, H. Kumano, and K. Uesugi, Phys. Status Solidi A 192, 224 (2002).

${ }^{34}$ A. Ohtomo, H. Kimura, K. Saito, T. Makino, Y. Segawa, H. Koinuma, and M. Kawasaki, J. Cryst. Growth 214/215, 284 (2000).

${ }^{35}$ C. Bulutay, B. K. Ridley, and N. A. Zakhleniuk, Appl. Phys. Lett. 77, 2707 (2000); C. Klingshirn, Semiconductor Optics, 3rd ed. (Springer,
Heidelberg, 2006).

${ }^{36}$ P. Lawaetz, Phys. Rev. B 5, 4039 (1972).

${ }^{37}$ W. R. L. Lambrecht, S. Limpijumnong, and B. Segal, MRS Internet J. Nitride Semicond. Res. 4S1, G6.8 (1999); J. E. Jaffe, R. Pandey, and A. B. Kunz, Phys. Rev. B 43, 14030 (1991).

${ }^{38}$ A. B. M. A. Ashrafi, Y. Segawa, K. Shin, and T. Yao, Phys. Rev. B 72, 155302 (2005); A. B. M. A. Ashrafi, B.-P. Zhang, N. T. Bin, K. Wakatsuki, and Y. Segawa, Jpn. J. Appl. Phys., Part 1 43, 1114 (2004); A. Ashrafi and Y. Segawa, Dhaka Univ. J. Sci. 55, 155 (2007); A. B. M. A. Ashrafi, N. T. Binh, B.-P. Zhang, and Y. Segawa, Appl. Phys. Lett. 84, 2814 (2004); A. B. M. A. Ashrafi, Y. Segawa, K. Shin, and T. Yao, Appl. Surf. Sci. 249, 139 (2005) 